\title{
Heidegger e a transformação da fenomenologia: a aproximação da hermenêutica e o afastamento de Husserl
}

\author{
[Heidegger and the transformation of phenomenology: \\ the rapprochement with hermeneutics and the departure \\ from Husserl]
}

Juliana Missaggia*

\section{Resumo}

Neste artigo analisamos a transformação da fenomenologia, realizada por Heidegger a partir da inserção de elementos próprios da hermenêutica. Para tanto, procuramos mostrar o modo como o filósofo relaciona a fenomenologia com noções como facticidade e ontologia, desse modo se afastando radicalmente da concepção pregada por Husserl - sobretudo quanto ao tipo de cientificidade que esse último defende ser possível para a filosofia.

Palavras-chave: Heidegger; Husserl; Fenomenologia; Hermenêutica.

\begin{abstract}
In this paper we analyze the way Heidegger, by enclosing elements pertaining to hermeneutics, managed to transform phenomenology as a discipline. To this end, we seek to show how the philosopher connects phenomenology to notions such as facticity and ontology, thereby radically departing from the conception held by Husserl - especially with regard to the kind of scientific status that the latter maintains to be possible for philosophy.
\end{abstract}

Key-words: Heidegger; Husserl; Phenomenology; Hermeneutics.

Muito se diz sobre a mudança de paradigma promovida pela obra Ser e Tempo a partir do método fenomenológico, cuja origem está em Edmund Husserl, professor de Heidegger. Hoje, porém, já é consenso entre os estudiosos da obra heideggeriana que as intuições de sua obra magna são, na verdade, fruto de um progressivo amadurecimento do pensamento do filósofo ao longo dos anos 20. Com a publicação das Gesamtausgabe podemos perceber como foi necessária uma longa reflexão, o que envolveu

* Doutora em Filosofia. Professora de Filosofia na Universidade Católica de Pernambuco. E-mail: jumissaggia@gmail.com.

Ano 15 • n. 1 • jan./jun. 2015 - 135 
tanto a apropriação da filosofia da tradição, como uma nova significação da fenomenologia a partir do confronto com questões até então não resolvidas por ela.

Uma dessas modificações, que está entre as mais importantes, é a transformação da fenomenologia a partir da inserção de elementos da hermenêutica. Tais mudanças não apenas geraram conflitos entre Heidegger e Husserl, mas também trouxeram a dificuldade de determinar quais os critérios para definir a fenomenologia e qual sua relação com a hermenêutica. $\mathrm{O}$ próprio Heidegger, no parágrafo $7 \mathrm{de}$ Ser e Tempo, afirma que seguirá a fenomenologia. Mas mesmo nesse tratamento ainda provisório do que consistiria tal fenomenologia - por meio da decomposição da palavra em fenômeno e lógos -, é possível perceber que não se trata do termo exatamente no mesmo sentido daquele elaborado por Husserl ${ }^{1}$.

O distanciamento de Heidegger em relação ao seu professor fica claro se levarmos em consideração o contexto e as motivações do projeto fenomenológico husserliano. Sua intenção era formular uma ciência rigorosa, que servisse de base para todos os demais conhecimentos. Husserl, cuja formação era na área da matemática, estava inicialmente interessado na fundamentação da aritmética, mas aos poucos seus estudos de lógica, assim como a influência de Brentano, o levam diretamente para a filosofia. Essa influência, assim como a de Bolzano, é bastante visível nos seus primeiros trabalhos e algumas das importantes intuições de Husserl surgem a partir do confronto com a obra desses autores ${ }^{2}$. Sua filosofia madura se dedica ao estudo da consciência a partir do ponto de

\footnotetext{
${ }^{1}$ Sobre esse ponto, afirma Mulhall (MULHALL, Stephen. Heidegger and 'Being and Time'. London: Routledge, 1997, p. 22): “(...) quando, no fim de sua introdução a Ser e Tempo, ele [Heidegger] reivindica o título de fenomenologia para sua obra, reconhece a influência e originalidade de Husserl, mas deliberadamente falha em estabelecer qualquer análise detalhada da sua relação com o projeto husserliano. No lugar disso, oferece uma análise etimológica do termo e deriva seu próprio projeto disso".

2 Para informações sobre a história da formação filosófica de Husserl ver MOHANTY, Jitendra N. The Development of Husserl's Thought. In Barry Smith and David Woodruff Smith, eds. The Cambridge Companion to Husserl. Cambridge and New York: Cambridge University Press, 1995 e DRUMMOND, John J. Historical dictionary of Husserl's philosophy. Lanham: Scarecrow Press, 2008.
} 
vista do eu, sujeito pensante, estando, portanto, inserida no paradigma das filosofias da consciência.

O ponto fundamental que levou Husserl à formulação do método fenomenológico foi a busca por uma fundamentação transcendental $^{3}$ do conhecimento. Nesse sentido, sua concepção de filosofia é clara: deve se tratar de uma "ciência que fundamente com radical autenticidade" e de uma "ciência universal". Assim, tal como Descartes, Husserl parte da tentativa de fundamentação radical do conhecimento, sobre bases indubitáveis. Para tanto, é necessário buscar um princípio de evidência que seja em si mesmo auto-fundamentado - o que, no projeto cartesiano, é encontrado através do cogito. Nenhum saber prévio pode ter validade nesse contexto de exigência epistemológica, o que faz com que o conhecimento de todas as ciências seja desconsiderado.

Husserl procura, então, por uma evidência apodítica, que define como um modo de certeza que tem a característica "não somente de ser, como toda evidência, certeza do ser das coisas ou fatos objetivos evidentes em si, mas de revelar (...) a impossibilidade absoluta de que se conceba seu não ser" ${ }^{\prime \prime}$. Desse modo, o filósofo pretende descrever um juízo onde não há a necessidade de adequar a apresentação da coisa a algo externo a sua própria apresentação, pois esta se mostra de maneira autoevidente, sem ser preciso recorrer a nada além dela mesma para sua verificação, pois no próprio ato de concepção da coisa já está implicada a impossibilidade da sua não existência.

3 Sobre o conceito de transcendental em Husserl, de acordo com Drummond (DRUMMOND, 2008, p. 203-4): "Husserl, em geral, assume este sentido kantiano [como condições subjetivas que pertencem à possibilidade de experienciar todo e qualquer objeto, e filosofia transcendental é o conhecimento $a$ priori dessas condições], mas também o modifica em aspectos importantes. Para Husserl, 'transcendental' não se refere principalmente às condições subjetivas para a possibilidade de qualquer experiência, mas sim às estruturas universais de qualquer experiência possível (ou experiência de um certo tipo). Para Husserl, além disso, o transcendental é um campo de investigação, um 'ser' devidamente caracterizado como 'consciência do mundo (enquanto experienciado)'. O transcendental, em outras palavras, é caracterizado pela relação intencional entre consciência e mundo e é, em primeiro lugar e principalmente, o campo de sentido (Sinn)".

${ }^{4}$ HUSSERL, Edmund. Cartesianische Meditationen und Pariser Vorträge. Ed. Stephan Strasser. Den Haag: Martinus Nijhoff, 1950, §3, p. 49.

${ }^{5}$ Ibidem, §6, p. 56. 
Seguindo o caminho já trilhado por Descartes - sem, no entanto, chegar ao mesmo lugar - Husserl estabelece que a atitude natural, que nos leva a tomar como verdadeira a tese da existência do mundo, não pode ser sustentada diante da exigência de uma evidência apodítica, pois ao conceber o mundo sua existência não aparece como indubitável. Assim, somente podemos ter como ponto de partida o "eu penso" cartesiano, que, no contexto das investigações fenomenológicas, se estende para toda a corrente de cogitationes do ego puro transcendental. Esse será, sobretudo, o objeto de estudo da fenomenologia husserliana: os próprios vividos intencionais $^{6}$, isto é, as vivências da consciência intencional.

Diante disso, pode-se antever o quão radicais foram as alterações ao projeto fenomenológico realizadas por Heidegger: enquanto seu professor partia da busca por uma ciência rigorosa, da fundamentação radical para o conhecimento, da rejeição aos pressupostos e da análise das estruturas e vividos da consciência, Heidegger resolve apontar para os elementos da hermenêutica que estão necessariamente implicados em qualquer atividade, questionando a concepção de filosofia que guiou a tradição e procurando evidenciar seu caráter interpretativo, fáctico e histórico, marcado por pressupostos inescapáveis.

De fato, o que está em questão na busca por uma "hermenêutica da facticidade" é mais do que um interesse por apontar para o caráter interpretativo da filosofia. Heidegger está, na verdade, questionando a própria filosofia, não somente em sua história (enquanto filosofia da tradição), mas também em suas possibilidades mais fundamentais. O que está em jogo não é apenas o trabalho por definir as dificuldades, erros ou acertos dos diversos filósofos e sistemas filosóficos, mas sim de buscar um campo

6 Seguimos aqui a tradução brasileira para a expressão alemã "Intentionales Erlebnis", que a traduz por "vivido intencional". O mesmo termo aparece traduzido como "intentional experience" ou "intentive mental process" em inglês. Por vivido, em um sentido amplo inicial, Husserl compreende todas as vivências que o cogito abrange: não somente "eu penso", mas também "percebo", "recordo", "imagino", "julgo", "desejo", e assim por diante (HUSSERL, Edmund. Ideen zu einer reinen Phänomenologie undphänomenologischen Philosophie. Erstes Buch. Allgemeine Einfuhrung in die reine Phänomenologie. Ed. Karl Schuhmann. Den Haag: Martinus Nijhoff, 1976, §34, p. 61). Todo esse fluxo contínuo e diverso do processo da consciência é enquadrado como seus vividos.

138 • Universidade Católica dePernambuco 
genuíno para o filosofar enquanto uma atividade do Dasein. Heidegger está ciente de que sua intenção envolve necessariamente uma tomada de posição sobre os princípios desse filosofar e sobre suas características fundamentais, no sentido de determinar o que é a filosofia, quais devem ser seus pressupostos e qual deve ser sua metodologia.

Em primeiro lugar, é importante marcar a relação fundamental que existe, para Heidegger, entre a filosofia fenomenológica e a ontologia: "fenomenologia em sentido restrito é fenomenologia da constituição. Fenomenologia em sentido amplo inclui a ontologia" ". A fenomenologia trata da constituição da estrutura e dos conteúdos da consciência de objetos que possuem diversas características. Ao procurar apreender os objetos como entes que possuem diferentes modos de ser e analisá-los sobre esse viés, a fenomenologia acaba por converter-se em um estudo ontológico. De fato, essa relação é o que garante os próprios fundamentos para a investigação ontológica, pois "é somente através da fenomenologia que a ontologia correspondente é estabelecida em uma base firme e mantida em um percurso ordenado no tratamento dos problemas" $"$.

Desse modo, Heidegger procura evidenciar as implicações não explicitadas do próprio projeto inicial husserliano: se a fenomenologia trata da constituição da consciência, ela deve também ser uma ontologia, pois do contrário não vai tratar suficientemente do modo de ser dos objetos da consciência. Além disso, uma vez que a filosofia fenomenológica que Heidegger pretende desenvolver possui um caráter hermenêutico - conforme o título de um de seus cursos: "Ontologia: hermenêutica da facticidade" -, a principal das ontologias a ser elaborada será aquela que se relaciona diretamente com a interpretação da facticidade: a análise do ser do Dasein. Essa não é, evidentemente, uma tarefa fácil e Heidegger reconhece que considerações tão gerais sobre a filosofia não garantem um esclarecimento adequado de suas bases. Somente na própria atividade de filosofar poderíamos encontrar seus fundamentos legítimos, pois é

7 HEIDEGGER, Martin. (GA 63). Ontologie (Hermeneutik der Faktizität) (Sommersemester 1923). Frankfurt am Main: Vittorio Klostermann, 1995, p 2.

${ }^{8}$ Ibidem, p. 2. 
justamente ao filosofar que eles são colocados à prova.

Heidegger diz, inclusive, ser surpreendente que a filosofia de seu tempo busque tão arduamente um fundamento mas seja incapaz de perceber a base na qual seus próprios pressupostos se sustentam. Ao, por exemplo, buscar dados fundamentais, muitas vezes os filósofos tomam os dados das ciências empíricas como "fatos brutos", sem perceber que eles já são fruto de uma teoria e metodologia específicas. Para ele, "o caráter metódico imanente desse comportamento do ponto de partida, isto é, daquilo que é pertinente para sua realização, permanece notavelmente indeterminado em filosofia" ". O filósofo se posiciona contra a ideia de que filosofia e ciências empíricas sejam campos relacionados, que deveriam compartilhar métodos, pressupostos e objetivos semelhantes.

Ainda que tomemos como característica fundamental da filosofia sua tendência para proceder através da classificação dos objetos em um todo ordenado e dotado de sentido, devemos perceber que isso não é tão simples quanto parece. Em uma distinção de segunda ordem, podemos questionar o tipo de sistema do qual partimos para a classificação. Tal sistema pode ser dado de antemão em seus fundamentos, podendo ser aberto ou fechado, ou pode ser em princípio indeterminado, de modo que só possamos perceber sua configuração durante o próprio processo de classificar.

Segundo Heidegger, "tendo o caráter de processo, esse sistema móvel é evidentemente algo 'mais profundo' do que o tipo de sistema estático e mais objetivo" ${ }^{\text {" }}$. Isso se explica pela própria natureza da atividade de filosofar: ela possui um caráter de realização e atualização que é dado sempre em um horizonte temporal. Um sistema pré-determinado e fechado peca contra a própria base temporal de qualquer atividade cognoscitiva e acaba por cair na mesma atitude ingênua do conhecimento empírico.

Ao enumerar os aspectos fundamentais da filosofia, porém, Heidegger parece a princípio bastante tradicional e, em alguns aspectos, próximo à concepção de Husserl: 1) seria essa uma

\footnotetext{
${ }^{9}$ Ibidem, p. 60.

${ }^{10}$ Ibidem, p. 61.
} 
filosofia objetiva e científica, oposta à filosofia da visão de mundo (Weltanschauungsphilosophie) - onde prevaleceriam os meros "pontos de vista" - e contrária ao relativismo sem bases; 2) enquanto objetiva, tal filosofia procura estabelecer as bases de fundamentação até mesmo para as filosofias de visões de mundo, pois permite tornar claros os termos que possibilitam uma concordância entre os interlocutores; 3) no entanto, ao contrário do que afirmam muitos, essa filosofia só pode ser considerada objetiva na medida em que está intimamente relacionada com a vida fáctica ${ }^{11}$ : "enquanto algo dinâmico, o sistema possui precisamente o caráter do processo da vida mesma""12;4) na medida em que está em relação com a vida fáctica, mas ao mesmo tempo não é meramente subjetiva, tal filosofia pode ser considerada universal e concreta.

É claro que aqui surge, em primeiro lugar, a dificuldade de compreender o que Heidegger entende por noções como objetivo, científico, universal e concreto. Poderíamos facilmente pensar que ao atribuir essas características à filosofia, ele estaria sustentando um projeto nos mesmos termos daquele de Husserl, na medida em que tais pretensões de cientificidade e universalidade eram a marca da fenomenologia husserliana. No entanto, dado o que já observamos sobre as intenções da nova metodologia de Heidegger, é evidente que não podemos entender sua filosofia do mesmo modo como a de seu professor.

Essa questão é fundamental na medida em que implica a compreensão do próprio caráter da nova filosofia heideggeriana e parece gerar paradoxos: se, como vimos, Heidegger sustentava uma distinção entre filosofia e ciência, no sentido de que seriam atividades essencialmente diferentes, como pode afirmar que a filosofia é científica? Em que sentido uma filosofia que tem como ponto de partida o Dasein concreto em sua vida fáctica pode ser universal e objetiva? Se a hermenêutica da facticidade envolve de modo inerente uma relação com a historicidade e o horizonte temporal, como entender essas afirmações que sustentam ser a

\footnotetext{
${ }^{11}$ Para mais detalhes sobre o conceito de "vida fáctica", ver COURTINE, JeanFrançois, MARQUET, Jean-François (eds.) De l'herméneutique de la facticité à la métaphysique du Dasein. Paris: Vrin, 1996.

${ }^{12}$ HEIDEGGER, 1995, p. 64.
} 
filosofia uma atividade oposta aos "pontos de vista" e a todo e qualquer relativismo?

Para responder a tais questões, é preciso entender a base radicalmente distinta da fenomenologia desenvolvida nesse período. Em primeiro lugar, Heidegger afirma que a filosofia deve ser objetiva e científica em oposição à filosofia relativista que busca uma mera visão de mundo. Isso não implica, no entanto, que o filósofo utilize essas expressões no mesmo significado que elas têm para a noção de rigor científico pregado por Husserl ou mesmo pelas ciências empíricas. Trata-se justamente do contrário: Heidegger não acredita que os procedimentos metodológicos que estão por trás dessas concepções de ciência sejam adequados para a filosofia, porém também quer deixar explícito que rejeitá-los não significa necessariamente aderir a uma filosofia relativista que se baseie em simples opiniões. No seu caso, existe a preocupação de buscar um método apropriado que possa exprimir genuinamente a experiência da vida fáctica, mas sem cair em um relativismo sem fundamentos; nesse sentido, haveria um aspecto objetivo e "científico" em sua análise.

Que a sua filosofia tenha como ponto de partida a facticidade da vida não se segue que não possua nenhum tipo de base segura, mas, ao contrário, é justamente por causa disso que pode ser considerada universal e concreta: partir da facticidade e da historicidade é o único meio possível para quem pretende descrever as coisas como realmente são. Qualquer tentativa de analisar os fenômenos como coisas isoladas e estáticas ou como fatos fora do mundo, que ocorrem somente "dentro da cabeça" do sujeito, são ilusões. A questão é não ignorar o que é em verdade o mais universal e concreto: a própria vida fáctica na qual ocorrem as experiências $^{13}$.

13 É bastante interessante a interpretação de Crowell (CROWELL, Steven. Husserl, Heidegger, and Space of Meaning: Paths Toward Transcendental Phenomenology. Evanston, Ill.: Northwestern University Press, 2001, p. 138-9): "Se o sentido metodológico da virada de Heidegger à facticidade não é levado em consideração, sua distinção entre weltschauung e ciência primordial colapsa. Se a facticidade, enquanto o Dasein-em-acontecimento na filosofia, é entendido como a determinação histórico-cultural empírica do 'sujeito', o ponto de partida fáctico pode ser concebido somente histórica e culturalmente em relação a visões de mundo. Assim, ainda que a filiação de Heidegger à facticidade renegue certos aspectos da concepção de Husserl do ego transcendental, o texto não oferece

142 • Universidade Católica de Pernambuco 
Todo ser humano necessariamente compreende a si mesmo - ainda que possa extrair disto muitas interpretações - como um ente dentro do mundo, que faz coisas, lida com objetos e com outros entes semelhantes a si. Que tal vivência ocorra num fluxo temporal é algo evidente a todos, ainda que não se torne um objeto de reflexão. Passar a refletir sobre o tempo e outras questões é uma possibilidade, uma escolha que podem fazer esses entes; escolher por essa em detrimento de outras atividades é um tipo de comportamento, que seria o comportamento daquele que filosofa. $\mathrm{O}$ fato de que qualquer experiência seja essencialmente temporal e o homem seja sempre "fruto de seu tempo", não impede que a filosofia por ele produzida possua uma base segura: devemos buscar sua fundamentação justamente a partir de seu caráter temporal. Ou seja, não é que fenomenologia heideggeriana rejeite a ideia de fundamentação, mas apenas que o tipo de fundamentação que acredita adequada e possível é distinta da fundamentação última que buscam Husserl e outros filósofos ${ }^{14}$.

nenhum fundamento para ver isso como uma rejeição das aspirações transcendentais da fenomenologia. Isso permanece um esforço para identificar esses aspectos transcendentais ou categoriais do 'sujeito' (situado) que faz da investigação filosófica algo possível. Por essa razão há uma duplicação na temática do método filosófico: possibilitar o acesso ao 'objeto' filosófico é ao mesmo tempo clarificar aquele através do qual tal acesso é estabelecido: o filósofo. (...). Contra a objeção de que qualquer relação com a 'situação factual' impediria a reivindicação filosófica de 'validade absoluta' e, portanto, implicaria em ceticismo ou relativismo, Heidegger objeta que tais argumentos formais simplesmente ignoram 'o sentido da realização (Vollzüge) do conhecimento filosófico...e o sentido de sua relação com o objeto' (GA 61: 164). (...) Dizer que a validade filosófica não está em que suas pressuposições possam ser 'provadas' como universalmente válidas, ou em que alguém consiga 'constranger' os outros a concordar, não significa - como as interpretações personalistas de Heidegger sugerem - que Heidegger está rejeitando a ideia de 'validade universal' ou de 'concordância' em filosofia. Antes, isso expressa uma peculiaridade da investigação filosófica sobre a qual também Husserl insiste". Ver HEIDEGGER, Martin. (GA 61). Phänomenologische Interpretationen zu Aristoteles (Wintersemester 1921/22). Frankfurt am Main: Vittorio Klostermann, 1985.

${ }^{14}$ Desenvolvi a questão acerca da fundamentação na filosofia heideggeriana, no seguinte artigo: MISSAGGIA, Juliana. Fundamento último ou falibilismo: aproximações do problema da fundamentação a partir da filosofia heideggeriana. Sapere Aude-Revista de Filosofia, v. 3, n. 5, p. 123-141, 2012. Ver também o estudo de Mafalda Blanc: BLANC, Mafalda F. $O$ fundamento em Heidegger. Lisboa: Piaget, 1984. 
Heidegger reconhece a dificuldade de procurar estabelecer as bases para uma filosofia de caráter hermenêutico, mas não tem dúvidas de que tal tarefa envolve a busca por um método adequado, que permita descrever os fenômenos fundamentais envolvidos na facticidade. Segundo o filósofo, "por meio das considerações mais necessárias sobre o método, iremos fazer brevemente a passagem explícita de entender o como da pesquisa em uma forma vazia para assumi-la na atualização" "15; ou seja, de acordo com o procedimento fenomenológico adequado, devemos manter em aberto a forma da pesquisa para encontrar sua forma concreta durante a atualização ao, justamente, pesquisar.

Um dos fenômenos fundamentais da facticidade seria a chamada posição prévia (Vorhabe): "olhar para algo e ver isso, definindo o que é visto, (...) implica já antecipadamente 'possuir' o que é visto como um ente de um modo ou outro". Essa atitude de "antecipação" em relação ao significado do ente que é apreendido "pode ser designada como posição prévia" respeito à compreensão do Dasein fáctico, que já possui uma visão de totalidade significativa em relação a todos os fenômenos: o contato com o ente não acontece de modo "neutro", mas sim já é sempre determinado de acordo com o modo como o Dasein concebe a realidade. Se vejo um objeto semelhante a um violão pela primeira vez (um bandolim, por exemplo), posso já inferir devido a meus conhecimentos prévios - que deve tratar-se de um instrumento musical. Uma pessoa, porém, que jamais viu instrumentos musicais feitos de madeira e cordas, dificilmente pensaria que aquele estranho objeto tem a função de produzir música.

A maneira metodologicamente apropriada de apreender a posição prévia $^{17}$ acontece através de concebê-la como uma

${ }^{15}$ HEIDEGGER, 1995, p. 79.

${ }^{16}$ Ibidem, p. 80.

17 Há, além da posição prévia, outros dois conceitos fundamentais da hermenêutica da facticidade: a visão prévia e a concepção prévia. Segundo Inwood (INWOOD, Michael. Dicionário Heidegger. Rio de Janeiro: Jorge Zahar Editor, 2002): "Auslegung envolve pressuposições, uma 'estrutura prévia' [VorStruktur] assim como uma 'estrutura-como' [Als-struktur] (ST, 151). Isto envolve três elementos: 1. 'posição prévia' [Vorhabe], a compreensão geral do ente a ser interpretado e da 'totalidade conjuntural' [Bewandtnisganzheit] na qual ele se encontra. 2. Vorsicht, no alemão comum 'prudência, circunspecção', mas 
indicação formal:

A posição prévia deve ser examinada e apropriada de maneira mais próxima, de modo que a inteligibilidade vazia da indicação formal possa ser preenchida ao olhar em direção à sua fonte de intuição concreta. A indicação formal é mal compreendida sempre que é tratada como uma proposição universal fixa e usada para fazer deduções a partir e com um modo de dialética construtivista. Tudo depende de nosso entendimento ser guiado a partir do conteúdo indefinido e vago - mas ainda assim inteligível - da indicação, na maneira de ver correta. Para obter êxito nesse modo de olhar, pode e deve ser de auxílio uma medida preventiva que procure rejeitar determinadas maneiras de olhar que são dominantes na situação de pesquisa no momento particular e que, por parecerem relevantes, recaem sobre nós ${ }^{18}$.

Como o próprio nome diz, indicação formal ${ }^{19}$ tem por intenção apontar, indicar uma direção para a qual devemos olhar. E, assim como todo o ato de apontar, há uma incompletude inerente a esse método: a ação de apontar só está completa em seu significado quando alguém olha na direção apontada. Nas indicações formais não há uma determinação concluída dos conceitos filosóficos, mas sim uma primeira aproximação. Ao procurar proceder de acordo com o método das indicações formais, dois mal-entendidos bastante comuns em filosofia devem ser evitados: o esquema sujeito-objeto e o preconceito da ausência de pressupostos e preconcepções.

O primeiro consiste no clássico problema epistemológico de explicar a relação entre duas esferas que seriam heterogêneas: a esfera subjetiva (sujeito, mente) e a esfera objetiva (objeto, mundo). De acordo com essa concepção, "a consciência é um 'eu penso' e, portanto, um ego, um ego-pólo, centro dos atos” em

considerado por Heidegger de forma literal como 'visão prévia'; eu pouso minha visão sobre o que eu quero interpretar ou sobre o aspecto que quero interpretar. 3 . Vorgriff, usualmente 'antecipação', mas literalmente 'concepção prévia', associada, para Heidegger, com Begriff, 'conceito'. Eu só posso interpretar as coisas em função dos conceitos à minha disposição".

${ }^{18}$ HEIDEGGER, 1995, p. 80.

19 Para maiores detalhes sobre o conceito de "indicações formais", ver STREETER, Ryan. Heidegger's Formal Indication: a Question of Method in Being and Time. Man and World, vol. 30 (1977).

Ano 15 • n. 1 • jan./jun. 2015 - 145 
relação ao qual está em oposição enquanto objetividade: "entes, objetos, coisas naturais, coisas de valor, bens" $" 20$. Tal dualidade acaba por gerar longas discussões teóricas sobre como entender a natureza da relação entre sujeito e objeto: se o objeto depende do sujeito, ou o contrário, ou se há uma mútua dependência e de qual tipo seria, etc. Segundo Heidegger, a superação para tal dicotomia é fundamental para a filosofia não perder-se em pseudo-questões; Husserl, em suas Investigações Lógicas, já teria apontado o caminho para a solução desse problema, especialmente através de seu conceito de intencionalidade ${ }^{21}$.

O segundo mal-entendido a ser evitado, do qual o projeto husserliano seria vítima, é a posição segundo a qual pode haver algum tipo de observação que seja livre de qualquer perspectiva dotada de preconcepção. Essa ideia pode ser ainda mais nociva que a anterior, na medida em que possui a aparência de ser uma garantia para a "verdadeira" filosofia, de caráter científico e objetivo. A pretensão daqueles que a defendem seria que pudéssemos apreender os fenômenos sem nenhum tipo de ideia preconcebida.

Porém, mesmo supondo que isso fosse possível, "até uma visão sem preconcepções é uma visão e tem, enquanto tal, um modo de ver particular", isto é, a própria ideia de não ter preconcepção alguma já é um ponto de vista entre outros e, nesse sentido, possui a preconcepção de que não devemos ter preconcepções. Segundo Heidegger, não podemos fugir do fato de que qualquer modo de ver é "em si algo histórico, ligado ao Dasein (...), e não um em-si quimérico e fora do tempo",22. Essa é a preconcepção defendida por Heidegger: alguma preconcepção é necessária. Enquanto seres históricos, já estamos desde sempre inseridos em um mundo previamente dotado de significado pela tradição. Ainda que possamos questionar o significado sustentado

\footnotetext{
${ }^{20}$ HEIDEGGER, 1995, p. 81.

${ }^{21}$ Parece-nos que a maneira como Heidegger procura superar a dicotomia sujeitoobjeto e mente-mundo difere do modo husserliano de tratar da questão. Isso se deve, principalmente, devido às suas diferenças quanto às noções de intencionalidade e redução. Um conceito fundamental para a compreensão desse aspecto na filosofia heideggeriana seria o conceito de mundo. No entanto, não cabe aprofundar aqui essa questão.

${ }^{22}$ HEIDEGGER, 1995, p. 82.

146 • Universidade Católica dePernambuco
} 
pela tradição da qual fazemos parte, devemos reconhecer que é dele que partimos.

Assim sendo, Heidegger modifica o método fenomenológico de modo substancial: uma vez que sustenta uma compreensão da atividade filosófica como necessariamente histórica e interpretativa, não há como conciliar sua concepção de fenomenologia com aquela de Husserl, para quem o método exigia a busca por uma fundamentação última para o conhecimento. Nesse sentido, a fenomenologia desenvolvida por Heidegger implica em uma modificação considerável no projeto husserliano como um todo: a abordagem a partir da historicidade e a centralidade do papel do Dasein como um ser-no-mundo histórico, distancia a fenomenologia da esfera transcendental pura.

Ainda assim, como vimos, o ponto de vista heideggeriano não deve ser confundido com um mero relativismo, pois sua ideia de filosofia envolve compreender a própria situação hermenêutica em todos os seus elementos, o que inclui a consciência da historicidade do conhecimento filosófico e dos pressupostos inerentes a qualquer atividade temporal e interpretativa. Portanto, embora o afastamento de Heidegger da posição de Husserl seja evidente já seus trabalhos do começo dos anos 20 , tal alteração no método fenomenológico não implica em abrir mão da busca pelas estruturas que determinam a atividade filosófica e a formulação de conceitos próprios da filosofia.

\section{Referências}

BLANC, Mafalda F. O fundamento em Heidegger. Lisboa: Piaget, 1984. COURTINE, Jean-François, MARQUET, Jean-François (eds.) De l'herméneutique de la facticité à la métaphysique du Dasein. Paris: Vrin, 1996.

CROWELL, Steven. Husserl, Heidegger, and Space of Meaning: Paths Toward Transcendental Phenomenology. Evanston, Ill.: Northwestern University Press, 2001.

DRUMMOND, John J. Historical dictionary of Husserl's philosophy. Lanham: Scarecrow Press, 2008.

INWOOD, Michael. Dicionário Heidegger. Rio de Janeiro: Jorge Zahar Editor, 2002.

MISSAGGIA, Juliana. Fundamento último ou falibilismo: aproximações do problema da fundamentação a partir da filosofia heideggeriana. Sapere 
Aude-Revista de Filosofia, v. 3, n. 5, p. 123-141, 2012.

MOHANTY, Jitendra N. The Development of Husserl's Thought. In Barry Smith and David Woodruff Smith, eds. The Cambridge Companion to Husserl. Cambridge and New York: Cambridge University Press, 1995.

MULHALL, Stephen. Heidegger and 'Being and Time'. London: Routledge, 1997.

HEIDEGGER, Martin. (GA 61). Phänomenologische Interpretationen zu Aristoteles (Wintersemester 1921/22). Frankfurt am Main: Vittorio Klostermann, 1985.

(GA 63). Ontologie (Hermeneutik der Faktizität) (Sommersemester 1923). Frankfurt am Main: Vittorio Klostermann, 1995.

HUSSERL, Edmund. Cartesianische Meditationen und Pariser Vorträge. Ed. Stephan Strasser. Den Haag: Martinus Nijhoff, 1950. . Ideen zu einer reinen Phänomenologie undphänomenologischen Philosophie. Erstes Buch. Allgemeine Einfuhrung in die reine Phänomenologie. Ed. Karl Schuhmann. Den Haag: Martinus Nijhoff, 1976.

STREETER, Ryan. Heidegger's Formal Indication: a Question of Method in Being and Time. Man and World, vol. 30 (1977). 